\title{
Frequency of Interferon-Resistance Conferring Substitutions in Amino Acid Positions 70 and 91 of Core Protein of the Russian HCV $1 b$ Isolates Analyzed in the T-Cell Epitopic Context
}

\author{
V. S. Kichatova $\mathbb{D}^{1,}{ }^{1,2,3}$ K. K. Kyuregyan $\left(\mathbb{D},{ }^{1,2,3}\right.$ N. V. Soboleva, ${ }^{1}$ A. A. Karlsen, ${ }^{1,2,3,4}$ \\ O. V. Isaeva, ${ }^{2,3}$ M. G. Isaguliants, ${ }^{1,4,5}$ and M. I. Mikhailov ${ }^{2,3}$ \\ ${ }^{1}$ Chumakov Federal Scientific Center for Research and Development of Immune-and-Biological Products of Russian Academy of \\ Sciences, Moscow 108819, Russia \\ ${ }^{2}$ Russian Medical Academy of Continuous Professional Education, Moscow 125993, Russia \\ ${ }^{3}$ Mechnikov Research Institute for Vaccines and Sera, Moscow 105064, Russia \\ ${ }^{4}$ NF Gamaleja Research Center of Epidemiology and Microbiology, Moscow 123098, Russia \\ ${ }^{5}$ Riga Stradins University, Riga LV-1007, Latvia
}

Correspondence should be addressed to V.S. Kichatova; vera_kichatova@mail.ru and K. K. Kyuregyan; karen-kyuregyan@yandex.ru

Received 29 August 2017; Accepted 29 November 2017; Published 7 February 2018

Academic Editor: Pedro A. Reche

Copyright (c) 2018 V. S. Kichatova et al. This is an open access article distributed under the Creative Commons Attribution License, which permits unrestricted use, distribution, and reproduction in any medium, provided the original work is properly cited.

\begin{abstract}
Amino acid substitutions $\mathrm{R} 70 \mathrm{Q} / \mathrm{H}$ and $\mathrm{L} 91 \mathrm{M}$ in $\mathrm{HCV}$ subtype $1 \mathrm{~b}$ core protein can affect the response to interferon and are associated with the development of hepatocellular carcinoma. We found that the rate of R70Q/H in HCV $1 \mathrm{~b}$ from Russia was $31.2 \%$, similar to that in HCV strains from Asia (34.0\%), higher than that in the European $(18.0 \%, p=0.0010)$, but lower than that in the US HCV $1 \mathrm{~b}$ strains $(62.8 \%, p<0.0001)$. Substitution L91M was found in $80.4 \%$ of the Russian $\mathrm{HCV} 1 \mathrm{~b}$ isolates, higher than in Asian isolates $(43.8 \%, p<0.0001)$. Thus, a significant proportion of Russian HCV $1 \mathrm{~b}$ isolates carry the unfavorable $\mathrm{R} 70 \mathrm{Q} / \mathrm{H}$ and/or $\mathrm{L} 91 \mathrm{M}$ substitution. In silico analysis of the epitopic structure of the regions of substitutions revealed that both harbor clusters of T-cell epitopes. Peptides encompassing these regions were predicted to bind to a panel of HLA class I molecules, with substitutions impairing peptide recognition by HLA I molecules of the alleles prevalent in Russia. This indicates that HCV 1b with R70Q/H and L91M substitutions may have evolved as the immune escape variants. Impairment of T-cell recognition may play a part in the negative effect of these substitutions on the response to IFN treatment.
\end{abstract}

\section{Introduction}

Approximately 177.5 million people worldwide are infected with the hepatitis C virus (HCV). In $60-80 \%$ of cases, infection results in the chronic liver disease; 10 to $25 \%$ progress to cirrhosis and hepatocellular carcinoma (HCC) [1-4], the second most common cause of cancer death worldwide after the lung cancer [5]. HCV infection is associated with at least half of the HCC cases [6]. In patients with hepatitis $\mathrm{C}$, treatment with the directacting antivirals (DAAs) of the second generation results in the sustained virological response (SVR) in 98-99\% cases. Unfortunately, due to the high cost and limited availability of DAAs, clinical practice in low- to moderateincome countries still relies on the pegylated interferon and ribavirin (PEG-IFN/RBV) therapy.

Infections with $\mathrm{HCV}$ genotype 1 that still predominate (in $48 \%$ of HCV-infected people), specifically HCV $1 \mathrm{~b}$ 
(in $23 \%$ of $\mathrm{HCV}$-infected people [4]), have been repeatedly associated with poor prognosis [7-11]. In chronic hepatitis $\mathrm{C}$, infection with HCV $1 \mathrm{~b}$ increases the rate of progression to fibrosis and cirrhosis and the risk of HCC development compared to infections with other HCV genotypes [8-12]. $\mathrm{HCV}$ genotype 1 infection is also an important prognostic factor of poor SVR to PEG-IFN/RBV treatment, with the response rate for genotypes 2 and 3 reaching $80 \%$, and for genotype 1, only 35 to $45 \%$ [13-15], being lower or tending to be lower for $\mathrm{HCV} 1 \mathrm{~b}$ carriers $(37 \%$ of patients with subtype $1 \mathrm{~b}$ and $45 \%$ of those with subtype 1a [16]). Several studies and meta-analyses have concluded that eradication of $\mathrm{HCV}$ with antiviral therapy reduces the risk of $\mathrm{HCC}$ in patients with chronic hepatitis $\mathrm{C}$, but the risk is not eliminated [17]. Wide spread of $\mathrm{HCV} 1 \mathrm{~b}$, high rate of progression to chronic hepatitis $\mathrm{C}$, poor response to PEG-IFN/RBV therapy still actual in poor to modest healthcare settings, and the increased risks of HCC development prompt continuation of the studies on the mechanisms of $\mathrm{HCV} 1 \mathrm{~b}$ resistance to interferon treatment.

Akuta et al. were the first to report that amino acid substitutions in positions 70 and 91 of the HCV 1b core protein associate with virological response to PEG-IFN/ RBV treatment. They found that change of arginine to glutamine or histidine in amino acid (aa) position 70 (R70Q and $\mathrm{R} 70 \mathrm{H}$ or $\mathrm{R} 70 \mathrm{Q} / \mathrm{H}$ ) and/or methionine in aa position 91 (L91M) was present in $100 \%$ of nonresponders who tested positive for HCV RNA at the end of 48 weeks of PEG-IFN/RBV treatment, but in only $42 \%$ of responders [18]. The significance of R70Q for HCV $1 \mathrm{~b}$ (and also for subtype $5 \mathrm{a}$ ) was confirmed in a series of later studies (see [19] for a review). R70Q was recorded as a predictive marker for the resistance to PEG-IFN/RBV also in the prolonged treatment regimens (72 weeks) and in the triple therapy with PEG-IFN/RBV and second-generation DAA [19-21]. A series of studies determined the frequency of these mutations in different population groups [22-24]. All, including the very recent ones, concluded that the nature of amino acid residues in aa position 70 of $\mathrm{HCV}$ core can help to distinguish patients who can still benefit from the affordable IFN-based therapy from those who must be treated with DAAs to prevent the evolution towards the end-stage liver disease [25]. The clinical significance of substitutions in aa position 91 of HCV $1 b$ is less well defined [19] and for other HCV genotypes either unclear [19] or not demonstrated [26-29]. Interestingly, clinical and experimental studies demonstrated the involvement of both of these mutations in hepatocellular carcinogenesis [30, 31]. Amino acid substitution R70Q/H appeared to be associated with cirrhosis and development of HCC even in PEG-IFN/RBV-treated patients achieving SVR [17, 22, 32-38]. Altogether, this motivates the need to characterize polymorphisms in $\mathrm{HCV} 1 \mathrm{~b}$ core protein and identify patients carrying "carcinogenic" HCV $1 \mathrm{~b}$ variants staying at a high risk of developing HCC even after the successful treatment.

The prevalence of $\mathrm{HCV}$ core polymorphisms R70Q/H and/or L91M in the territory of the Russian Federation was not characterized despite high incidence of $\mathrm{HCV}$ infections [39], the predominance of HCV 1 genotype, specifically of HCV 1 b subtype (up to 50\% [40-42]), and wide use of standard interferon therapy. In this study, we filled this gap and described the spread in the Russian Federation of HCV 1 b strains with $\mathrm{R} 70 \mathrm{Q} / \mathrm{H}$ and/or L91M substitutions in comparison to their spread in the other geographical regions and evaluated the effect of these substitutions on the recognition of these regions by the immune system of the patients.

\section{Materials and Methods}

2.1. Samples. The analysis included 313 sequences encoding $\mathrm{HCV}$ core amplified from the serum samples of patients with chronic hepatitis C collected during 2007-2014 in different regions of the Russian Federation: Moscow and the Moscow region $(n=238)$, Rostov/Rostov-on-Don $(n=12)$, Tuva/Kyzyl $(n=12)$, Khabarovsk $(n=36)$, Sverdlovsk/Yekaterinburg $(n=4)$, and Sakha/Yakutsk $(n=11)$. Age and gender were known for 117 individuals; 34 were females and 83 were males (the female to male ratio was $1: 2.4$ ). Mean age was $40 \pm 14$ years. All serum samples included into the database were from the general population with the exception of those from Moscow/Moscow region represented by the subgroup of the general population without known risk factors $(n=49)$ and intravenous drug users (IDUs; $n=45$ ). Written informed consent was obtained from each patient.

2.2. HCV Genotyping and Sequencing. HCV genotype and subtype were determined by the phylogenetic analysis of $\mathrm{HCV}$ core coding region; and for $\mathrm{HCV} 2 \mathrm{k} / 1 \mathrm{~b}$ recombinants, also of the NS5b region. Nucleic acid extraction was performed using QIAamp Viral RNA Mini Kit (QIAGEN, Hilden, Germany), or MagNA Pure Compact Nucleic Acid Isolation Kit I (Roche Applied Science, Mannheim, Germany), or Sileks MagNA kit (Sileks, Moscow, Russia). Reverse transcription and amplification was performed with Transcriptor First Strand cDNA Synthesis Kit and Fast Start High Fidelity PCR System (Roche Applied Science). HCV core coding region (nucleotide positions 273-1315 according to $\mathrm{HCV}$ la reference strain H77, GenBank accession number AF011753) was subjected to nested PCR with the following primers: outer forward $5^{\prime}$-GCT AGC CGA GTA GTG TTG GG-3'; outer reverse $5^{\prime}$-ACC AGT TCA TCATCA TAT YCC- $3^{\prime}$; inner forward $5^{\prime}$-GAA AGG CCT TGT GGT ACT GC-3'; and inner reverse $5^{\prime}$-TTC ATC ATA TTC CAT GCCA- $3^{\prime}$. The first and the second steps of PCR were as follows: $5 \mathrm{~min}$ at $94^{\circ} \mathrm{C}$, then 35 cycles of $45 \mathrm{sec}$ at $94^{\circ} \mathrm{C}$, $45 \mathrm{sec}$ at $55^{\circ} \mathrm{C}, 90 \mathrm{sec}$ at $72^{\circ} \mathrm{C}$, and final elongation for $7 \mathrm{~min}$ at $72^{\circ} \mathrm{C}$. PCR products of $1043 \mathrm{nt}$ length were cut and extracted from agarose gel using QIAquick Gel Extraction kit (QIAGEN). Sequencing was performed on an automated sequencer 3130 Genetic Analyzer (ABI, Foster City, USA) using Big Dye Terminator v.3.1 Cycle Sequencing Kit according to the manufacturer's protocol. The genotype was established by comparison sequences 
with GenBank reference sequences representative for all $\mathrm{HCV}$ genotypes.

2.3. HCV Sequence Database. Database of $313 \mathrm{HCV}$ sequences was supplemented with 94 sequences from GenBank geographically attributed to St. Petersburg $(n=42$ : AY070167-AY070169, AY070174.1, AY070178-AY070211, AY070214, AY070215, AY587844, and AY587845); Novosibirsk ( $n=47$ : DQ001223-DQ001264, DQ001267DQ001270, AH014196.2, and AH014197.2); and Moscow $(n=5:$ AF176573, KM054515, KM054516, KT983617, and $\mathrm{X} 71407)$. The complete database consisted of 407 sequences of the "Russian" HCV core of subtypes: 1a $(n=29), 1 \mathrm{~b}$ $(n=189)$, 3a $(n=171)$, and recombinant $2 \mathrm{k} / 1 \mathrm{~b}(n=18)$ (Table 1). Group of comparison consisted of $2210 \mathrm{HCV}$ core sequences from the Los Alamos database (LANL; https://hcv.lanl.gov/content/index) distributed as follows: Asia $(n=374)$, USA $(n=1343)$, and Europe $(n=497)$ (Table 1). Samples of the Russian patients infected with HCV1b formed a separate set divided into the subsets depending on the region of sample collection (Table 2). The geographical distribution of these subsets is illustrated by Supplementary Figure S1.

2.4. In Silico Analysis of HCV Core Sequences. Alignment of the nucleotide and predicted amino acid sequences of HCV were performed using MEGA 7.0.18. Prevalence of substitutions in amino acid positions 70 and 91 was calculated using Microsoft Office Excel. Phylogenetic analysis of HCV1b core sequences (Supplementary Figure S2) was done using a Bayesian likelihood-based algorithm implemented in Beast version 1.8.4 [43]. The SRD06 substitution model was used with a relaxed lognormal clock. Analysis was run over 700 million generations and trees were sampled every 70,000 generations, resulting in 70,000 trees. Trees were annotated with TreeAnnotator v.1.8.3 using a burn-in of 1000 trees and visualized with FigTree v.1.4.2 (Andrew Rambaut; http://tree.bio.ed.ac.uk/ software/figtree/). Search for T-cell epitopes in HCV core sequences was performed through EIDB database (http:// www.iedb.org) [44]. Epitope sequences were aligned with $\mathrm{HCV}$ core aa sequences using MEGA software.

2.5. Prediction of Presentation of HCV Core-Derived Peptides by HLA Class I and II Molecules. Amino acid sequences of HCV core of $189 \mathrm{HCV} 1 \mathrm{~b}$ were used to build the consensus sequence of "Russian" HCV 1b core (sequence in GenBank deposition). Consensus sequence was divided into nine amino acid- (aa-) long peptides with mandatory presence of aa residues 70 or 91 . Prediction of presentation of resulting HCV core-derived peptides by human leukocyte antigen class I molecules (HLA class I) was done on EPITOPE VACCINE OPTIMIZATION server (http://bio.med.ucm.es/ episopt.html) using EPISPOT tool (http://bio.med.ucm.es/ episopt.html; [45]). Analysis was carried for a selection of HLA I alleles prevalent in the Russian population based on the most representative dataset [46] and other data deposited in the Allele Frequency Net Database (http://www. allelefrequencies.net/pop6001c.asp?pop_id=3322; [47]).
Presentation by HLA class II molecules was evaluated using the NetMHCIIpan 3.1 program (http://www.cbs.dtu. $\mathrm{dk} /$ services/NetMHCIIpan-3.1) [48-50] for the region starting with 20 -mer peptide with the C-terminal aa 70 and ending with the 20-mer peptide with the N-terminal aa 91 . Analysis was done for the following: 275 HLA class II alleles DRB1*1101-DRB1*1195, DRB1*1301-DRB1*1399, and DRB1 $^{*} 1501-$ DRB1 $^{*} 1549$; and combination of alpha and beta chains DQA1*0101, DQA1*0102, DQA1*0301, DQA1*0501 with DQB1*0201, DQB1*0301, DQB1*0501, DQB1*0602, DQB1*0603, DQB1*0604, DQB1*0605, DQB1*0606, DQB1*0607, and DQB1*0608, selected based on the published data on the frequency of HLA class II alleles in the Russian Federation [46, 47, 51]. Strong binding was characterized by binding level $<2 \%$; weak binding, 2 to $10 \%$; no binding, $>10 \%$.

2.6. Statistical Analysis. Data analysis was performed using the http://Graphpad.com/. Statistical significance was evaluated by Fisher's exact test using parametric model, twotailed $p$ value $<0.05$ was considered statistically significant.

\section{Results}

3.1. Characteristics of the Set of HCV $1 b$ Sequences Used in the Study. The analysis included 313 sequences encoding HCV core amplified from the serum samples of patients with chronic hepatitis C collected during 2007-2014 from the general population in different regions of the Russian Federation, supplemented with 94 sequences from the GenBank ( $n=407$; Table 1). Sequence set included 189 HCV 1b sequences derived from the territory of the Russian Federation, 140 obtained here, and 49 sequences from the GenBank. We performed their phylodynamic analysis with the focus on $140 \mathrm{HCV} 1 \mathrm{~b}$ isolates (Supplementary Figure S2). The analysis illustrated a long history of HCV $1 \mathrm{~b}$ evolution on the Russian territory, with current strains having an average time of separation from the "foreign" strains of approximately $15 \pm 5$ years, the oldest strains separating $60 \pm 15$ years ago (Supplementary Figure S2). No clusters were revealed, indicating that sequences were not related. HCV $1 \mathrm{~b}$ sequences with $\mathrm{R} 70 \mathrm{Q} / \mathrm{H}$ and/or L91M substitutions did not form any clusters either, being distributed evenly throughout the phylogenetic tree (Supplementary Figure S2). This demonstrates that the selected sequences are geographically genuine, adequately reproduce the diversity of $\mathrm{HCV} 1 \mathrm{~b}$ in the territory of the Russian Federation, and are, therefore, suitable for the analysis of frequency of occurrence of amino acid substitutions in positions 70 and 91 in the territory of the Russian Federation.

3.2. Frequency of Substitutions in aa Positions 70 and 91 of HCV 16 from the Russian Federation Compared to Other Geographical Regions. Substitution R70Q was found in $27.0 \%$ and $\mathrm{R} 70 \mathrm{H}$ in $4.2 \%$ of the Russian HCV $1 \mathrm{~b}$ isolates, which was similar to their frequencies in the isolates from Asia and in all countries taken together $(p>0.05)$, but significantly higher than the frequency of R70Q and of $\mathrm{R} 70 \mathrm{H}$ in 
TABLE 1: Frequency of occurrence of substitutions at amino acid positions 70 and 91 of the nucleocapsid (core) protein of HCV genotypes 1a, $1 \mathrm{~b}$, and $3 \mathrm{a}$ in different population groups (in \%).

\begin{tabular}{|c|c|c|c|c|c|c|}
\hline \multirow{2}{*}{ HCV genotype } & \multirow{2}{*}{ Substitutions } & \multicolumn{5}{|c|}{ Geographical variation in \% of sequences variants in $\mathrm{HCV}$ of different genotypes } \\
\hline & & Russia & Europe & Asia & USA & Total \\
\hline \multirow{6}{*}{ 1a } & nn samples & $n=29$ & $n=149$ & $n=27$ & $n=1087$ & $n=1292$ \\
\hline & Q70 & 3.4 & 0.7 & 0 & 1.7 & 1.5 \\
\hline & $\mathrm{H} 70$ & 0 & 0 & 0 & 0.1 & 0.1 \\
\hline & M91 & 0 & 0 & 0 & 0 & 0 \\
\hline & Both* & 0 & 0 & 0 & 0 & 0 \\
\hline & None** & 96.6 & 99.3 & 100 & 98.2 & 98.4 \\
\hline \multirow{6}{*}{$1 b$} & nn samples & $n=189$ & $n=316$ & $n=224$ & $n=218$ & $n=947$ \\
\hline & Q70 & 27.0 & 17.7 & 31.3 & 59.6 & 32.4 \\
\hline & $\mathrm{H} 70$ & 4.2 & 0.3 & 2.7 & 3.2 & 2.3 \\
\hline & M91 & 80.4 & 85.8 & 43.8 & 86.2 & 74.9 \\
\hline & Both* & 27.5 & 15.5 & 16.1 & 54.6 & 27.0 \\
\hline & None ${ }^{* *}$ & 15.9 & 11.7 & 38.4 & 5.5 & 17.4 \\
\hline \multirow{6}{*}{$3 a$} & nn samples & $n=171$ & $n=28$ & $n=123$ & $n=38$ & $n=360$ \\
\hline & Q70 & 2.9 & 7.1 & 9.8 & 0 & 5.3 \\
\hline & $\mathrm{H} 70$ & 0 & 0 & 0 & 0 & 0 \\
\hline & M91 & 0.6 & 0 & 0 & 0 & 0.3 \\
\hline & Both* & 0 & 0 & 0 & 0 & 0 \\
\hline & None** & 96.5 & 92.9 & 90.2 & 100 & 94.4 \\
\hline
\end{tabular}

*Substitutions in both aa 70 and $91 ;{ }^{* *}$ no substitutions.

Europe (17.7\%, $p=0.0179$; and $0.3 \%, p=0.0021$, resp.; Table 1). Substitution L91M was found in $80.4 \%$ of HCV $1 \mathrm{~b}$ isolates from Russia, likewise to Europe and worldwide, but more often than in the strains from Asia (43.8\%, $p<0.0001$; Table 1). Substitution R70Q was significantly more prevalent compared to substitution $\mathrm{R} 70 \mathrm{H}$ in all geographical regions including Russia. Frequency of occurrence of substitutions in positions 70 and 91 in $\mathrm{HCV}$ genotypes 1a and 3a was low (Table 1). Geographical distribution of amino acid variants in positions 70 and 91 for HCV subtypes 1a and $3 \mathrm{a}$ was similar, except for comparatively more frequent occurrence of R70Q in HCV $3 a$ strains from Asia (significantly more than in the Russian HCV subtype 3a strains; 9.8\% versus $2.9 \%, p=0.0204$; Table 1). All available core sequences of the recombinant HCV 2k/1b (18 from Russia and 4 from Europe) had no substitutions in either position 70 or 91 (data not shown).

\subsection{Pattern of Substitutions in aa Positions 70 and 91 in $\mathrm{HCV}$} 16 Strains in the Russian Federation. HCV $1 \mathrm{~b}$ variants with substitutions R70Q/H and L91M were evenly distributed in all eight regions of the Russian Federation assessed (Table 2). Differences were observed only between Moscow (R70Q/H, 40.4\%; L91M, 79.8\%) and Novosibirsk subcohorts (R70Q/H, 20.7\%, $p=0.0049$; L91M, 75.5\%, $p=0.0094)$. Substitution R70Q dominated over substitution $\mathrm{R} 70 \mathrm{H}$ in all studied cohorts (data not shown). Prevalence of R70Q/H and L91M mutations were similar in males and females ( $p=0.8286$ and $p=0.439$ for aa positions 70 and 91 , resp.). Comparison of subcohorts with a known year of sample collection demonstrated the accumulation of $\mathrm{R} 70 \mathrm{Q} / \mathrm{H}$ substitution over time: they were found in $19.6 \%$ of samples collected before 2005 and in $39.1 \%$ in samples collected in 2011-2014 ( $p=0.038$; Table 2). An increase in the frequency of occurrence of the substitution was observed only for position 70 but not for 91 (Figure 1).

Analysis of the Moscow cohort demonstrated similar frequency of $\mathrm{R} 70 \mathrm{Q} / \mathrm{H}$ and $\mathrm{L} 91 \mathrm{M}$ mutations among the general population and the intravenous drug users (IDUs) (R70Q/H: $38.7 \%$ versus $42.2 \%, p=0.8341$; L91M: $81.6 \%$ versus $77.7 \%, p=0.7979$; Table 2). Difference between these two population groups was observed only in aa residue in position 75: R75H/Q occurred in the general population more frequently than in IDUs $(52.6 \%$ and $46.6 \%$, resp.; $p=0.0423)$. Substitutions at aa position 75 were repeatedly detected in the earlier studies $[52,53]$, but their clinical significance is yet unclear.

3.4. Epitopic Analysis of the Region of HCV Core Containing Amino Acid Residues 70 and 91. Amino acid sequences of $\mathrm{HCV}$ core of $189 \mathrm{HCV} 1 \mathrm{~b}$ were used to build the consensus sequence of the "Russian" HCV 1b core, an "average" HCV sequence largely free from the patient-specific adaptations [54]. Epitopic analysis of the consensus HCV core using Immune Epitope Database and Analysis resource (http:// www.iedb.org) identified $183 \mathrm{CD} 4+$ and CD8+ $\mathrm{T}$ cell epitopes, with $14(7.7 \%)$ encompassing aa 70 and 29 (15.8\%) encompassing aa 91, respectively. Totally, $23.5 \%$ 


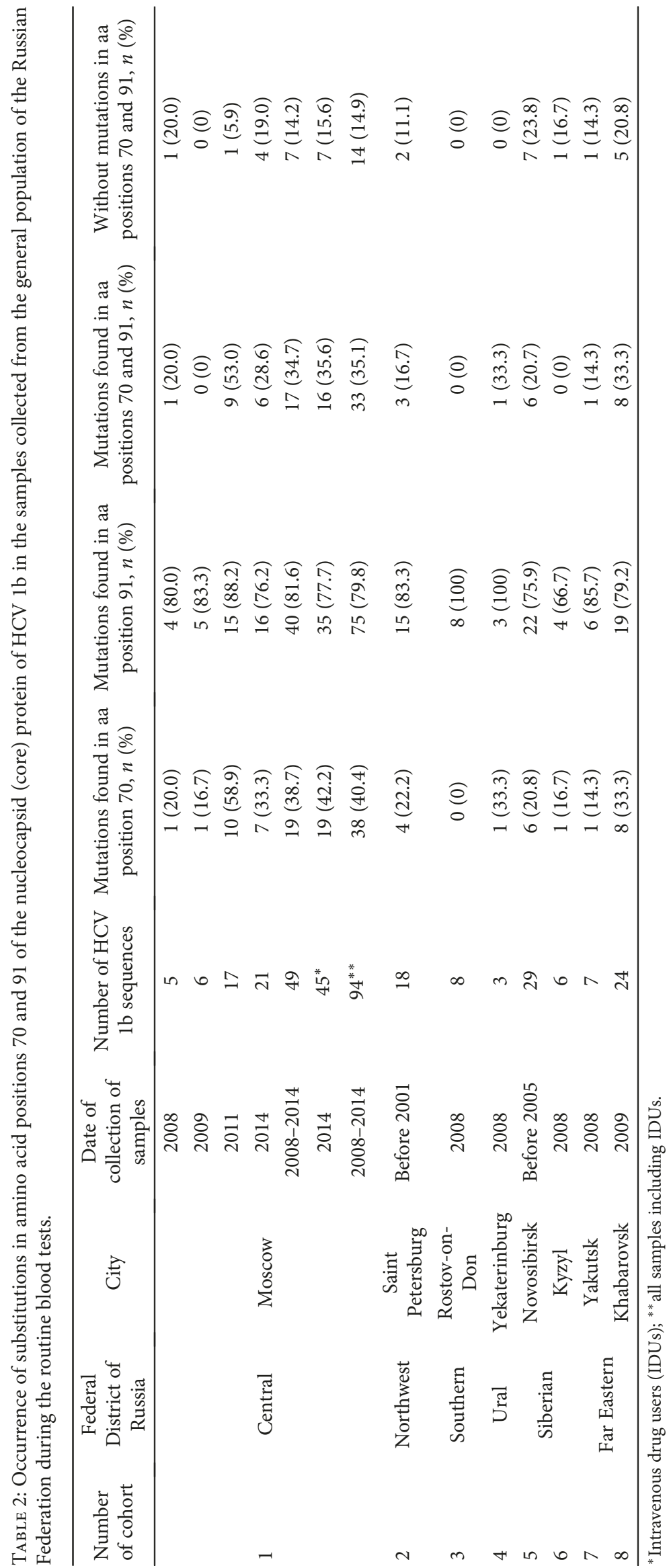




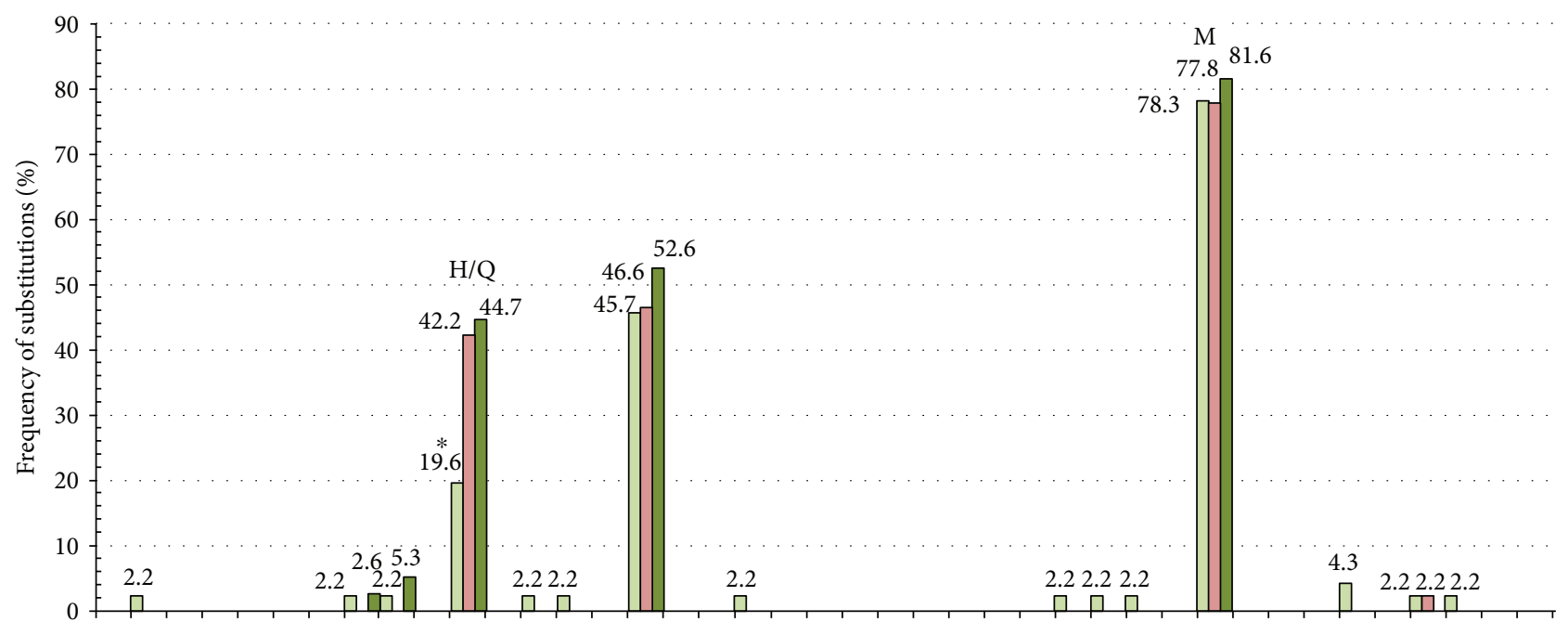

60616263646566676869707172737475767778798081828384858687888990919293949596979899100

$\mathrm{HCV}$ core aa position

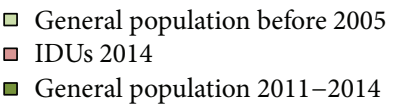

FIGURE 1: Frequency of amino acid substitutions in the region between aa 60 to 100 of the nucleocapsid (core) of HCV 1b, in samples collected before 2005 in the general population in Russia ("general population before 2005"; $n=46$ ), during 2011-2014 in Moscow/Moscow region in the general population ("general population 2011-2014"; $n=38$ ), and in intravenous drug users ("IDUs 2014"; $n=45$ ). *Frequency of occurrence of $\mathrm{R} 70 \mathrm{Q} / \mathrm{H}$ in the group "general population before 2005" (19.6\%) was significantly lower compared to "general population 2011-2014" (44.7\%, $p=0.0178)$ and "IDUs 2014 " $(42.2 \%, p=0.0240)$, while frequency of the substitution in the latter two groups did not differ.

of all T-cell epitopes within HCV core included either aa position 70 or 91 HCV 1 b core was found to harbor 8 epitopes encompassing aa 70 and 11 encompassing aa 91 (Supplementary Figure S3).

3.5. Prediction of Recognition of the Region of HCV $1 b$ Core Containing Amino Acid Residues 70 and 91 by HLA Class I and II Molecules. First, we analyzed how HCV core variants with and without mutations were recognized by HLA class I molecules. The complete list of HLA I alleles and peptides within HCV $1 \mathrm{~b}$ core capable to bind to them is presented in Supplementary Table S1 for regions aa 62 to 78 and S2 for aa 83 to 99 . From these lists, we selected HLA I alleles prevalent in the territory of the Russian Federation [28, 29] (Figure 2). Several alleles predicted to bind peptides with the wild type, but not with the mutant amino acid residues, were identified. For peptides encompassing aa position 70 , these were A3101, B0702, and B1516 and for aa position 91, A0202, A0205, and B0702 (Figure 2, Tables S1 and S2). HLA-B0702 allele, prevalent in the Russian population $(20.7 \%)$, turned to be of particular interest as it was predicted to bind peptides containing R70 and L91 but not their mutated variants containing Q70, or H70, and M91 (Figure 2, Tables S1 and S2).

We have also assessed if HCV core variants with and without substitutions can bind to HLA class II molecules. Since HLA class II are capable of binding up to 20 amino acid long peptides, we included in the analysis the consensus amino acid sequence of HCV 1b spanning 39 aa with aa positions 70 or 91 in the middle. Data on the frequency of HLA II alleles in the Russian population with high-resolution typing are limited. Based on the lowresolution analysis for HLA II DR, the most prevalent alleles are HLA II DRB101 (22.4\%), DRB104 (20.5\%), DRB107 (25.6\%), DRB111 (26.7\%), DRB113 (26.0\%), and DRB115 $(23.4 \%)[28,29]$. High-resolution data on the frequency of HLA II DQA1 and DQB1 alleles for ethnical Russians is available for only one geographical region of the Russian Federation (Astrakhan region) [30]. According to this data, the most prevalent alleles are as follows: DQA1*0101 (24.0\%), DQA1*0102 (34.3\%), DQA1*0301 (20.0\%), DQA1*0501 (47.3\%), DQB1*0201 (33.7\%), DQB1*0301 (39.3\%), DQB1 *0501 (20.3\%), and DQB1*0602-08 (36.0\%) [30]. Analysis of binding of these HLA II molecules with HCV corederived peptides done using NetMHCIIpan program included the total of 275 alleles. None of the HLA II DRB1 alleles prevalent in Russia were predicted to bind any aa fragment within the consensus HCV $1 \mathrm{~b}$ core sequence spanning aa positions 50 to 110 . Weak binding with the fragment aa 71 to 110 harboring aa 91 was predicted for alleles HLA-DQA1*0501-DQB1*0301, HLADQA1*0501-DQB1*0501, HLA-DQA1*0501-DQB1*0603, HLA-DQA1 ${ }^{*}$ 0501-DQB1 ${ }^{*} 0604$, HLA-DQA1 *0501-DQB1 ${ }^{*}$ 0607, HLA-DQA $1^{*} 0501-\mathrm{DQB} 1^{*} 0608$, HLA-DQA1*0301DQB1*0301, and HLA-DQA $1{ }^{*} 0301-\mathrm{DQB1}{ }^{*} 0501$ (exemplified by the data set in the Supplementary Table S3). The 


\begin{tabular}{|c|c|c|c|c|c|c|c|}
\hline \multirow{3}{*}{$\begin{array}{l}\text { Predicted } \\
\text { HLA } 1 \text { allele }\end{array}$} & \multicolumn{5}{|c|}{$\begin{array}{l}\text { Epitopes within HCV core encompassing regions } \\
\text { of subsitutes }\end{array}$} & \multirow{2}{*}{\multicolumn{2}{|c|}{$\begin{array}{l}\text { Prevalence based on low } \\
\text { resolution HLA } 1 \text { typing }\end{array}$}} \\
\hline & \multicolumn{3}{|c|}{ aa position 70} & \multicolumn{2}{|c|}{ aa position 91} & & \\
\hline & R70 & Q70 & $\mathrm{H} 70$ & L91 & M91 & HLA 1 type & Prevalence, \% \\
\hline A0201 & & & & $*$ & $*$ & \multirow{4}{*}{ A02 } & \multirow{4}{*}{50,0} \\
\hline A0202 & & & & * & & & \\
\hline A0205 & & & & * & & & \\
\hline A0209 & & & & $*$ & $*$ & & \\
\hline A2402 & & & & * & * & A24 & 20,3 \\
\hline A2902 & & & & * & * & A 29 & 3,2 \\
\hline A3101 & * & & & & & A31 & 3,9 \\
\hline B0702 & $*$ & & & * & & B07 & 20,7 \\
\hline B0801 & $*$ & * & * & & & B08 & 12,6 \\
\hline B1508 & & * & & & & & \\
\hline B1513 & * & * & * & & & B15 & 11,4 \\
\hline B1516 & * & & & & & & \\
\hline B2801 & & * & & & & & \\
\hline B2702 & * & * & * & & & & \\
\hline B2703 & & $*$ & & & & B27 & 8.8 \\
\hline B2704 & & $*$ & & & & & \\
\hline B2705 & * & & & & & & \\
\hline B2706 & * & * & * & & & & \\
\hline B3501 & & & & * & * & B35 & 20,6 \\
\hline B3909 & * & * & * & * & $*$ & B39 & 4,6 \\
\hline B4402 & $*$ & $*$ & & & & B44 & 18,0 \\
\hline B5101 & & & & * & $*$ & & \\
\hline B5102 & & & $*$ & * & $*$ & B51 & 9,6 \\
\hline B5103 & & & & & * & & \\
\hline B5301 & & & & * & * & B53 & 0,3 \\
\hline B5401 & & * & & & & B54 & No data \\
\hline B5502 & & * & * & & & B55 & 1,9 \\
\hline B5701 & $*$ & $*$ & $*$ & * & $*$ & B57 & 5.1 \\
\hline B2702 & * & $*$ & * & & & ינד & , \\
\hline
\end{tabular}

FIGURE 2: Prediction of binding of peptides encompassing aa 70 and 91 of nucleocapsid (core) protein of HCV $1 \mathrm{~b}$ to HLA I alleles prevalent in the Russian population. Binding prediction was done using EPISPOT tool (http://bio.med.ucm.es/episopt.html [45]). Allele frequency data is based on the data obtained from Allele Frequency Net Database [46, 47]. Predicted binding is depicted by an asterisk. HLA class I molecules binding only to the peptides containing wild-type amino acid residues R70 and/or L91 are shaded green; only variants with Q70, or H70, and/ or M91 mutations, red; binding regardless of the nature of amino acid residues in positions 70 and/or 91, blue.

binding was not affected by the nature of amino acid residue in position 91. No binding was predicted for the peptides spanning aa 50 to 90 harboring aa 70 (data not shown).

\section{Discussion}

The presence of substitutions $\mathrm{R}$ to $\mathrm{Q} / \mathrm{H}$ in aa position 70 of the nucleocapsid (core) of HCV $1 \mathrm{~b}$ can help distinguish patients who can still benefit from the affordable IFN-based therapy from those who do not respond and are at an increased risk of HCC development [17, 22, 25, 32-38]. There are also indications of the clinical significance of $\mathrm{L}$ to M substitution in aa position 91 of HCV 1b, although less well defined $[18,19]$. Here, we for the first time analyzed the frequency of occurrence of $\mathrm{R} 70 \mathrm{Q} / \mathrm{H}$ and $\mathrm{L} 91 \mathrm{M}$ substitutions in a set of 189 sequences of HCV 1b isolates derived from the territory of the Russian Federation. Phylogenetic analysis has shown that these sequences formed no clusters, and it evolved as a result of continuous viral circulation in the territory of the former Soviet Union, which indicates that they adequately represent the diversity of Russian $\mathrm{HCV} 1 \mathrm{~b}$ isolates. We found that $31.4 \%$ of the Russian HCV $1 \mathrm{~b}$ isolates harbor $\mathrm{R} 70 \mathrm{Q} / \mathrm{H}$, that is, almost one-third of individuals infected with HCV $1 \mathrm{~b}$ in the Russian Federation carry viral isolates that are potentially resistant to the standard PEG-IFN/RBV therapy and confer an increased risk of HCC development. Comparative analysis of HCV $1 \mathrm{~b}$ core variant distribution demonstrated a higher prevalence of unfavorable $\mathrm{R} 70 \mathrm{Q} / \mathrm{H}$ variants in the Russian Federation compared to the neighboring European countries. USA was 
the only region where the frequency of R70Q mutation appeared to be higher. At the same time, L91M substitution was found to be present in the majority of HCV $1 \mathrm{~b}$ strains circulating in all regions of the world, including the Russian Federation (except for Asia, where the predominant viral variant had L91). Analysis of the frequency of R70Q/H and L91M in HCV $1 \mathrm{~b}$ isolated in the different regions of the Russian Federation demonstrated the ubiquitous even distribution of these variants. Example of Moscow/Moscow region has also shown that $\mathrm{R} 70 \mathrm{Q} / \mathrm{H}$ and $\mathrm{L} 91 \mathrm{M}$ HCV $1 \mathrm{~b}$ variants had similar prevalence in the general population and in the high-risk group of intravenous drug users from the same geographical region, which excluded the influence of this risk group on the results of this study.

We have analyzed the prevalence of substitutions $\mathrm{R} 70 \mathrm{Q} / \mathrm{H}$ and L91M in all HCV $1 \mathrm{~b}$ core sequences from LANL $(n=898)$ regardless of the area of sample collection. Similar analysis has been performed by two independent research groups in 2010 [26] and in 2014 [19]. The frequency of occurrence of R70Q and R70H substitutions in HCV 1 b isolates in the study done in 2010 was significantly higher than in our analysis $(60 \%$ and $4 \%$ versus $32.9 \%$ and $1.7 \%$, resp., for all samples regardless of the time of collection; $p<0.01$ ), whereas the frequency of occurrence of L91M substitution was similar (71\% in 2010 [26] versus $69 \%$ in $2016, p>0.05)$. Interestingly, we registered an increase in the frequency of occurrence of R70Q/H variant in the Russian Federation between 2005 and 2014: $\mathrm{R} 70 \mathrm{Q} / \mathrm{H}$ variant was present in $19.6 \%$ of samples collected before 2005 and in $39.1 \%$ in samples collected in 2011-2014 ( $p<0.05$; Table 2$)$. This pointed at a positive selection of this variant in the Russian population with its prevalence increasing towards the levels observed worldwide.

We observed an increase in the frequency of substitutions in aa position 70, not elsewhere in this region of $\mathrm{HCV}$ core, suggesting that this substitution was not related to the changes in the other regions of the core protein. The latter is supported by the absence of covariance of the residues in amino acid position 70 with amino acid residues in other positions of $\mathrm{HCV}$ core, or elsewhere in HCV polyprotein [55]. This, together with the long history of evolution of HCV $1 \mathrm{~b}$ strains in the Russian territory, suggests that substitutions in aa position 70 of $\mathrm{HCV} 1 \mathrm{~b}$ core protein are not the compensatory ones. Although, Tasaka-Fujita et al. found polymorphisms at aa 70 to be associated with the efficiency of in vitro production of the infectious virus, with deteriorated virus production in $70 \mathrm{Q}$ strains resulting in the intracellular accumulation of $\mathrm{HCV}$ proteins [30]. Also, a recent study done in 112 Chinese patients with chronic HCV $1 \mathrm{~b}$ infection revealed that in patients infected with mixtures of $70 \mathrm{R}$ and $70 \mathrm{Q} /$ $\mathrm{H} \mathrm{HCV} 1 \mathrm{~b}$ strains (most of the patients in this study), viral kinetics of two strains changed synchronously during the treatment [56]. The latter data indicated that $\mathrm{R} 70 \mathrm{Q} / \mathrm{H}$ substitutions (i) do not improve viral replication fitness; (ii) have not evolved as a result of the selective pressure of PEGIFN $\alpha / R B V$ treatment; and (iii) do not confer an advantage in the viral replication/propagation under the treatment conditions [56]. Altogether, these point that positive selection of
$\mathrm{R} 70 \mathrm{Q} / \mathrm{H}$ is unrelated to the viral replication fitness, stressing the importance in the selection of the host-related factors.

Host factors are multiple and include alcohol consumption, age at infection, infections/coinfections, and genetic factors, such as gender, or single-nucleotide polymorphisms upstream of IL-28B [57-60]. Funaoka et al. using a virus culture system demonstrated the suppression of IFN signaling (IFN resistance) in cultured cells infected with 70Q/H HCV $1 b$ strains $\mathrm{HCV} 1 \mathrm{~b}$ infected with core mutation $(70 \mathrm{Q} / \mathrm{H})$, possibly induced by the IL-6-induced upregulation of SOCS3 [61]. HCV 1b-infected patients with 70Q had significantly higher homeostasis model assessment insulin resistance (HOMA-IR) scores compared to HCV $1 \mathrm{~b}$ patients without substitution in this position, suggesting that the substitution has a close relationship to insulin resistance [62]. Mechanistically, extracellular HCV core protein with substitution at position 70 was found to enhance IL-6 production and reduce adiponectin production from visceral adipose tissue, which can cause insulin resistance, hepatic steatosis, and ultimately development of HCC [63]. This, as well as other experimental and clinical studies identified a series of associations between substitutions in $\mathrm{HCV}$ core and such host-related factors as oxidative stress and HCVinduced metabolic disorders [64-66].

An important host genetic factor appeared to be the ethnicity. We have looked for the published data on the links between the response to standard treatment, host ethnicity, and prevalence of core mutations in different population groups. Unusually, poor response to PEGIFN $\alpha / \mathrm{RBV}$ treatment was repeatedly reported in the Afro-American patients compared to Caucasian Americans [67]. People of the African descent had lower chances of success with dual antiviral therapy compared with Caucasians. This was observed in the homogeneous populations with low rates of racial admixture assessed by self-reported ancestry, as well as in admixed populations when ancestry was assessed using genetic markers [68]. American patients of the African origins were found to less likely respond to treatment and achieve SVR than non-African-American patients [69]. Infected with genotype 1, they exhibited significantly lower decreases in the first-phase viral RNA, slower elimination of infected cells, and smaller declines in mean viral RNA over 1 month suggesting an impaired ability to block viral production in African-Americans [70]. On the contrary, Asian patients achieve higher sustained virologic response rates following IFN-based therapy than nonAsians [71]. Interestingly, for the Asian patients, superior virologic outcomes were observed also with different classes of DAAs alone or in combination [71] indicating that the outcomes were not determined by the effects of IFN. These observations fall in line with our findings that Asia is the place where the largest proportion of the virus has not yet acquired both $\mathrm{R} 70 \mathrm{Q} / \mathrm{H}$ and L91M mutations, whereas in America basically all $\mathrm{HCV} 1 \mathrm{~b}$ variants are already mutated (occurrence of nonmutated sequences in America is significantly lower than in Asia, Russia, or Europe; $p<0.0005$; Table 1).

Also, the treatment outcomes for chronic hepatitis $\mathrm{C}$ related to aa substitutions in aa positions 70 and 91 varied 
with ethnicity. The first studies demonstrating the importance of $\mathrm{R} 70 \mathrm{Q} / \mathrm{H}$ and $\mathrm{L} 91 \mathrm{M}$ substitutions in the core protein were carried in patients infected with HCV $1 \mathrm{~b}$ in Japan (18). However, they were not reproduced in all Japanese studies. Enomoto et al. identified the role in treatment response only of the amino acid substitutions in HCV NS5a, but not in the core protein [72]. A study of HCV 1b-infected Caucasian patients in Spain demonstrated a significant association with PEG-IFN/RBV treatment outcome with substitutions R62G, R70Q, and N110T [28]; in Saudi patients, with substitutions R70Q and A75; in Azerbaijani patients from Iran, with substitutions K43R, R70Q, L91M, and S106 [23]. Studies of the Caucasian patients infected with HCV $1 \mathrm{~b}$ in Sweden, and in Caucasians infected with HCV $1 \mathrm{~b}$ in the United States demonstrated significant association of PEG-IFN/RBV treatment outcome with substitutions in aa position 70 , but not in other aa positions including $91[26,27]$. Interestingly, despite the unusually poor response to PEG-IFN $\alpha / \mathrm{RBV}$ treatment in the Afro-American patients compared to Caucasian Americans, their isolates did not differ in the frequency of occurrence of amino residues in position 70 [27]. Also, the association of differential viral responses with polymorphisms in core aa position 70 demonstrated in the North American patients was weaker than in the Japanese studies [27]. On top of it, in the study of the correlates of PEGIFN $\alpha /$ RBV treatment response in the Chinese patients with chronic HCV $1 \mathrm{~b}$ infection, 70Q/H HCV $1 \mathrm{~b}$ strains exhibited the same virological response as the 70R strains [56]. Analysis of these studies demonstrated that the role of amino acid substitutions in positions other than 70 is discrepant, while substitutions in the position 70 predict poor IFN treatment response in patients of some, but not all ethnicities and nationalities.

While analyzing a broad scope of viral and host factors linking substitutions in aa positions 70 and 91 of HCV core with treatment response, these studies left out the issue of the adaptive immune response, and possible viral evolution under the pressure of the immune system of the host. Immune database analysis done here demonstrated that $\mathrm{R} 70 \mathrm{Q} / \mathrm{H}$ and $\mathrm{L} 91 \mathrm{M}$ substitutions are localized in the T-cell epitopic clusters and may interfere with the immune recognition of host cells infected with mutant virions, which would affect the spontaneous and also IFN therapy-driven immune clearance. Immune recognition in populations of different ethnicity varies; different ethnic groups have distinct and characteristic HLA allele frequencies, resulting in the differential immune recognition of the epitope-carrying regions depending on the haplotype of the host, which would differentially drive viral immune escape. In this context, the increasing prevalence of mutant HCV variants can be explained by an escape from the dominant types of immune pressure in a certain population, in relation to the regionally prevalent HLA types. Such HLA allele-specific mutation patterns were earlier described for HIV-1 [73].

The assumption that HLA allele specific immune pressure would result in the regionally variable patterns of immune escape mutations falls in line with uneven geographical distribution of HCV $1 \mathrm{~b} \mathrm{R} 70 \mathrm{Q} / \mathrm{H}$ and $\mathrm{L} 91 \mathrm{M}$ variants
(Table 1). Furthermore, in silico analysis carried here suggests that at least some of HLA I alleles prevalent in the Russian Federation, such as A02 and B07, are able to bind $70 \mathrm{R}$ and $91 \mathrm{~L}$ peptides but cannot bind peptides with $\mathrm{R} 70 \mathrm{Q} / \mathrm{H}$ or $\mathrm{L} 91 \mathrm{M}$ substitutions. At the same time, the role of HLA class II binding, hence of the T-helper cell or antibody response in immune selection, was predicted as negligible. Due to insufficiency of the high-resolution HLA typing data for the Russian Federation, our predictions of HLA I and HLA II binding with HCV core peptides were done on the low-resolution level. Even with these limitations, our data points at the involvement of HLA I- (but not HLA II-) specific alleles in the differential immune recognition of HCV $1 b$ variants with substitutions in aa positions 70 and 91, with the possibility for immune escape of the variants that have acquired $\mathrm{R} 70 \mathrm{Q} / \mathrm{H}$ and/or L91M. A very recent comparative analysis of the variation and selection in $\mathrm{HCV}$ genome demonstrated positive selection of HCV variants associated with HLA class I-driven CTL response (but not CD4+ Tcell response or RNA structure) [74]. Increasing frequency of occurrence of $\mathrm{HCV} 1 \mathrm{~b}$ variants bearing $\mathrm{R} 70 \mathrm{Q} / \mathrm{H}$ and L91M may result from such positive selection. Interestingly, a study conducted in one particular region of the Russian Federation among patients of the Russian ethnicity found that HLA I haplotypes A02/B07 and A03/B07 are associated with the higher rates of spontaneous $\mathrm{HCV}$ elimination and protection against the development of chronic infection [51]. Carriage of $\mathrm{A}\left({ }^{*}\right) 02$ was also found to predict SVR in a study done in the Caucasian American patients [75]. In patients with chronic hepatitis C, HLA I allele B07 was related to the resistance to active chronic liver disease indicating its association with recognition and clearance of HCV-infected hepatocytes [51]. These findings support the clinical significance of our observations, requesting further confirmatory studies with high-resolution genotyping of the population.

\section{Conclusions}

This is the first study characterizing the frequency of occurrence of IFN resistance-conferring mutations in human hepatitis $\mathrm{C}$ virus isolates circulating in the territory of the Russian Federation, and the first one, in which the spread of viral variants with substitutions in aa positions 70 and 91 may be associated with the positive selection under the pressure of immune response. Spread of $\mathrm{R} 70 \mathrm{Q} / \mathrm{H}$ and L91M HCV $1 \mathrm{~b}$ variants may result from an immune escape from the CTL response. The immunogenetic background of $\mathrm{HCV}$-infected individuals (racial variations in viral-specific immunity) would then determine both the differences in geographical distribution of certain viral variants and ethnical differences in their response to treatment. The choice of treatment strategy for patients with HCV is increasingly based on the personalized approach. It takes into account many viral and host factors. Screening of HCV $1 \mathrm{~b}$-infected patients for unfavorable mutations in the core region could be a useful tool to identify the individuals in need of IFN-free treatment regimens employing DAA. In the future, after 
complete implementation of IFN-free regimens, analysis of polymorphisms at position 70 of $\mathrm{HCV} 1 \mathrm{~b}$ core will remain relevant to identify patients at higher risk of HCC development who require immediate treatment.

\section{Conflicts of Interest}

The authors declare that there is no conflict of interest regarding the publication of this paper.

\section{Authors' Contributions}

V. S. Kichatova and K. K. Kyuregyan contributed equally to this work.

\section{Acknowledgments}

This study was supported by the grant of the Russian Science Foundation (Project ID 15-15-30039). Mobility and training of the researchers was supported by the grants of the Swedish Institute (TP 09272/2013 and PI 19806/2016).

\section{Supplementary Materials}

Supplementary 1. Figure S1: geographical origins of samples of hepatitis C patients infected with $\mathrm{HCV} 1 \mathrm{~b}$ from the Russian Federation used in the analysis of frequency of substitutions in HCV core amino acid positions 70 and 91. Data on the sample set is presented in Table 2.

Supplementary 2. Figure S2: phylogenetic tree for the complete $\mathrm{HCV}$ core sequences covering nucleotide positions 342-915 according to HCV 1a reference strain H77 (GenBank accession number NC004102) built using a Bayesian likelihood-based algorithm; detailed overview of the tree fragments (A;B). Sequences of the Russian origins are underlined. Sequences with wild type aa in positions 70 and 91 (R70, L91) are colored green; with mutated R70Q/H, orange; with M91L substitution, blue; with substitutions in both 70 and 91(R70Q/H, M91L), red.

Supplementary 3. Figure S3: T-cell epitopes in the consensus amino acid sequence of nucleocapsid (core) of HCV $1 \mathrm{~b}$ encompassing amino acids 70 (A) and 91 (B) localized using Immune Epitope Database and Analysis resource (http:// www.iedb.org).

Supplementary 4. Table S1: presentation by HLA I alleles of 9-mer peptide variants derived from the region between aa 62 and 78 of the nucleocapsid (core) of HCV 1 b encompassing aa 70, predicted using EPISPOT tool (http://bio.med.ucm .es/episopt.html; EPISPOT [25]). Nine amino acid long peptides were chosen based on the consensus amino acid sequence of nucleocapsid (core) protein of HCV $1 \mathrm{~b}$ variants isolated in the Russian Federation. Upper row: position of amino acids in HCV core; \% $(n=189)$, frequency of occurrence of the respective variant in a set of $189 \mathrm{HCV} 1 \mathrm{~b}$ sequences; potential epitopes, selection of potential CTLepitopes localized within the peptide seqeunce; PPC, population protection coverage (PPC) calculated as the proportion of the population that can potentially mount an immune response to the peptide computed using known frequences of the HLA I alleles that can present the peptide; HLA class I binding profile lists HLA class I molecules predicted to present the peptide. NF, not found.

Supplementary 5. Table S2: presentation by HLA I alleles of 9-mer peptide variants derived from the region between aa 83 and 99 of the nucleocapsid (core) of HCV 1b encompassing aa 91, predicted using EPISPOT tool (http://bio.med.ucm.es/ episopt.html; EPISPOT [45]). Nine amino acid long peptides were chosen based on the consensus amino acid sequence of nucleocapsid (core) protein of HCV $1 \mathrm{~b}$ variants isolated in the Russian Federation. Upper row: position of amino acids in HCV core; \% $(n=189)$, percentage of respective variant in a set of $189 \mathrm{HCV}$ 1b sequences; PPC, population protection coverage (PPC) calculated as the proportion of the population that can potentially mount an immune response to the peptide computed using known frequences of the HLA I alleles that can present the epitope; HLA I binding profile lists HLA I molecules predicted to present the epitope. NF, not found.

Supplementary 6. Table S3: NetMHCIIpan 3.1 engine [48] predicts only weak binding of HCV $1 \mathrm{~b}$ core peptides encompassing amino acid residue 91 to a limited number of human HLA class II molecules. Peptide predicted to be recognized is boxed in green and aa position 91 in red. Strong binding is characterized by binding level $<2 \%$; weak binding, 2 to 10\%; no binding, $>10 \%$.

\section{References}

[1] T. J. Liang, B. Rehermann, L. B. Seeff, and J. H. Hoofnagle, "Pathogenesis, natural history, treatment, and prevention of hepatitis C," Annals of Internal Medicine, vol. 132, no. 4, pp. 296-305, 2000.

[2] C. W. Shepard, L. Finelli, and M. J. Alter, "Global epidemiology of hepatitis C virus infection," The Lancet Infectious Diseases, vol. 5, no. 9, pp. 558-567, 2005.

[3] J. Thompson Coon, G. Rogers, P. Hewson et al., "Surveillance of cirrhosis for hepatocellular carcinoma: systematic review and economic analysis," Health Technology Assessment, vol. 11, no. 34, pp. 1-206, 2007.

[4] A. Petruzziello, S. Marigliano, G. Loquercio, A. Cozzolino, and C. Cacciapuoti, "Global epidemiology of hepatitis C virus infection: an up-date of the distribution and circulation of hepatitis C virus genotypes," World Journal of Gastroenterology, vol. 22, no. 34, pp. 7824-7840, 2016.

[5] International Agency for Research on Cancer, World Cancer Report 2014, World Health Organization, Geneva, 2014.

[6] G. L. Armstrong, A. Wasley, E. P. Simard, G. M. McQuillan, W. L. Kuhnert, and M. J. Alter, "The prevalence of hepatitis C virus infection in the United States, 1999 through 2002," Annals of Internal Medicine, vol. 144, no. 10, pp. 705-714, 2006.

[7] P. Amoroso, M. Rapicetta, M. E. Tosti et al., "Correlation between virus genotype and chronicity rate in acute hepatitis C," Journal of Hepatology, vol. 28, no. 6, pp. 939-944, 1998, 9672167.

[8] C. Bréchot, "Hepatitis C virus: molecular biology and genetic variability," Digestive Diseases and Sciences, vol. 41, Supplement 12, pp. 6S-21S, 1996. 
[9] T. Poynard, P. Bedossa, P. Opolon, and The OBSVIRC, METAVIR, CLINIVIR, and DOSVIRC Groups, "Natural history of liver fibrosis progression in patients with chronic hepatitis C," The Lancet, vol. 349, no. 9055, pp. 825-832, 1997.

[10] B. Le Guen, G. Squadrito, B. Nalpas, P. Berthelot, S. Pol, and C. Brechot, "Hepatitis C virus genome complexity correlates with response to interferon therapy: a study in French patients with chronic hepatitis C," Hepatology, vol. 25, no. 5, pp. 12501254, 1997.

[11] J. B. Nousbaum, S. Pol, B. Nalpas et al., "Hepatitis C virus type $1 \mathrm{~b}$ (II) infection in France and Italy," Annals of Internal Medicine, vol. 122, no. 3, pp. 161-168, 1995.

[12] S. Raimondi, S. Bruno, M. U. Mondelli, and P. Maisonneuve, "Hepatitis $\mathrm{C}$ virus genotype $\mathrm{lb}$ as a risk factor for hepatocellular carcinoma development: a meta-analysis," Journal of Hepatology, vol. 50, no. 6, pp. 1142-1154, 2009.

[13] M. W. Fried, M. L. Shiffman, K. R. Reddy et al., "Peginterferon alfa-2a plus ribavirin for chronic hepatitis $\mathrm{C}$ virus infection," The New England Journal of Medicine, vol. 347, no. 13, pp. 975-982, 2002.

[14] S. J. Hadziyannis, H. Sette Jr., T. R. Morgan et al., "Peginterferon- $\alpha 2 \mathrm{a}$ and ribavirin combination therapy in chronic hepatitis C: a randomized study of treatment duration and ribavirin dose," Annals of Internal Medicine, vol. 140, no. 5, pp. 346355, 2004.

[15] M. P. Manns, J. G. McHutchison, S. C. Gordon et al., "Peginterferon alfa- $2 \mathrm{~b}$ plus ribavirin compared with interferon alfa$2 \mathrm{~b}$ plus ribavirin for initial treatment of chronic hepatitis $\mathrm{C}$ : a randomised trial," The Lancet, vol. 358, no. 9286, pp. 958965, 2001.

[16] A. Andriulli, F. Morisco, A. M. Ippolito et al., "HCV genotype 1 subtypes ( $1 \mathrm{a}$ and $1 \mathrm{~b}$ ): similarities and differences in clinical features and therapeutic outcome," Hepatology International, vol. 9, no. 1, pp. 52-57, 2015.

[17] R. H. Westbrook and G. Dusheiko, "Natural history of hepatitis C," Journal of Hepatology, vol. 61, no. 1, pp. S58-S68, 2014.

[18] N. Akuta, F. Suzuki, H. Sezaki et al., "Association of amino acid substitution pattern in core protein of hepatitis $C$ virus genotype $1 \mathrm{~b}$ high viral load and non-virological response to interferon-ribavirin combination therapy," Intervirology, vol. 48, no. 6, pp. 372-380, 2005.

[19] A. El-Shamy and H. Hotta, "Impact of hepatitis C virus heterogeneity on interferon sensitivity: an overview," World Journal of Gastroenterology, vol. 20, no. 24, pp. 7555-7569, 2014.

[20] N. Akuta, F. Suzuki, M. Hirakawa et al., "Amino acid substitution in hepatitis $\mathrm{C}$ virus core region and genetic variation near the interleukin $28 \mathrm{~B}$ gene predict viral response to telaprevir with peginterferon and ribavirin," Hepatology, vol. 52, no. 2, pp. 421-429, 2010.

[21] N. Akuta, F. Suzuki, Y. Seko et al., "Determinants of response to triple therapy of telaprevir, peginterferon, and ribavirin in previous non-responders infected with HCV genotype 1," Journal of Medical Virology, vol. 84, no. 7, pp. 1097-1105, 2012.

[22] N. Akuta, F. Suzuki, Y. Kawamura et al., "Amino acid substitutions in the hepatitis $\mathrm{C}$ virus core region are the important predictor of hepatocarcinogenesis," Hepatology, vol. 46, no. 5, pp. 1357-1364, 2007.

[23] T. Okanoue, Y. Itoh, H. Hashimoto et al., "Predictive values of amino acid sequences of the core and NS5A regions in antiviral therapy for hepatitis C: a Japanese multi-center study," Journal of Gastroenterology, vol. 44, no. 9, pp. 952-963, 2009.
[24] R. C. Jaspe, Y. F. Sulbarán, M. Z. Sulbarán, C. L. Loureiro, H. R. Rangel, and F. H. Pujol, "Prevalence of amino acid mutations in hepatitis $\mathrm{C}$ virus core and NS5B regions among Venezuelan viral isolates and comparison with worldwide isolates," Virology Journal, vol. 9, no. 1, p. 214, 2012.

[25] C. Sultana, G. Oprişan, M. D. Teleman et al., "Impact of hepatitis $\mathrm{C}$ virus core mutations on the response to interferonbased treatment in chronic hepatitis C," World Journal of Gastroenterology, vol. 22, no. 37, pp. 8406-8413, 2016.

[26] E. Alestig, B. Arnholm, A. Eilard et al., "Core mutations, IL28B polymorphisms and response to peginterferon/ribavirin treatment in Swedish patients with hepatitis $\mathrm{C}$ virus genotype 1 infection," BMC Infectious Diseases, vol. 11, no. 1, article 124, 2011.

[27] M. J. Donlin, N. A. Cannon, E. Yao et al., "Pretreatment sequence diversity differences in the full-length hepatitis $\mathrm{C}$ virus open reading frame correlate with early response to therapy," Journal of Virology, vol. 81, no. 15, pp. 8211-8224, 2007.

[28] F. A. Di Lello, J. A. Mira, K. Neukam et al., "Core amino acid variation at position 110 is associated with sustained virological response in Caucasian patients with chronic hepatitis C virus 1b infection," Archives of Virology, vol. 159, no. 12, pp. 3345-3351, 2014.

[29] F. S. Alhamlan, M. N. Al-Ahdal, N. Z. Khalaf et al., "Hepatitis $C$ virus genotype 1 : how genetic variability of the core protein affects the response to pegylated-interferon and ribavirin therapy," Journal of Medical Virology, vol. 86, no. 2, pp. 224-234, 2014.

[30] M. Tasaka-Fujita, N. Sugiyama, W. Kang et al., "Amino acid polymorphisms in hepatitis $C$ virus core affect infectious virus production and major histocompatibility complex class I molecule expression," Scientific Reports, vol. 5, article 13994, 2015.

[31] A. El-Shamy, M. Pendleton, F. J. Eng, E. H. Doyle, A. Bashir, and A. D. Branch, "Impact of HCV core gene quasispecies on hepatocellular carcinoma risk among HALT-C trial patients," Scientific Reports, vol. 6, article 27025, 2016.

[32] N. Akuta, F. Suzuki, Y. Seko et al., "Complicated relationships of amino acid substitution in hepatitis $\mathrm{C}$ virus core region and IL28B genotype influencing hepatocarcinogenesis," Hepatology, vol. 56, no. 6, pp. 2134-2141, 2012.

[33] S. Nakamoto, F. Imazeki, K. Fukai et al., "Association between mutations in the core region of hepatitis $\mathrm{C}$ virus genotype 1 and hepatocellular carcinoma development," Journal of Hepatology, vol. 52, no. 1, pp. 72-78, 2010.

[34] N. Akuta, F. Suzuki, M. Hirakawa et al., "Amino acid substitutions in hepatitis $\mathrm{C}$ virus core region predict hepatocarcinogenesis following eradication of $\mathrm{HCV}$ RNA by antiviral therapy," Journal of Medical Virology, vol. 83, no. 6, pp. 1016-1022, 2011.

[35] Y. Seko, N. Akuta, F. Suzuki et al., "Amino acid substitutions in the hepatitis $\mathrm{C}$ virus core region and lipid metabolism are associated with hepatocarcinogenesis in nonresponders to interferon plus ribavirin combination therapy," Intervirology, vol. 56, no. 1, pp. 13-21, 2013.

[36] A. El-Shamy, M. Shindo, I. Shoji, L. Deng, T. Okuno, and H. Hotta, "Polymorphisms of the core, NS3, and NS5A proteins of hepatitis $\mathrm{C}$ virus genotype $1 \mathrm{~b}$ associate with development of hepatocellular carcinoma," Hepatology, vol. 58, no. 2, pp. 555-563, 2013.

[37] N. Akuta, F. Suzuki, M. Kobayashi et al., "Impact of mutations at amino acid 70 in hepatitis $\mathrm{C}$ virus $(\mathrm{HCV})$ genotype $1 \mathrm{~b}$ core region on hepatocarcinogenesis following eradication of $\mathrm{HCV}$ 
RNA," Journal of Clinical Microbiology, vol. 53, no. 9, pp. 3039-3041, 2015.

[38] S. Kobayashi, T. Takeda, M. Enomoto et al., "Development of hepatocellular carcinoma in patients with chronic hepatitis $\mathrm{C}$ who had a sustained virological response to interferon therapy: a multicenter, retrospective cohort study of 1124 patients," Liver International, vol. 27, no. 2, pp. 186-191, 2007.

[39] H. Bailey, A. Turkova, and C. Thorne, "Syphilis, hepatitis C and HIV in Eastern Europe," Current Opinion in Infectious Diseases, vol. 30, no. 1, pp. 93-100, 2017.

[40] A. V. Shustov, G. V. Kochneva, G. F. Sivolobova et al., "Molecular epidemiology of the hepatitis C virus in Western Siberia," Journal of Medical Virology, vol. 77, no. 3, pp. 382-389, 2005.

[41] S. N. Kuzin, E. I. Samokhvalov, E. E. Zabotina et al., "Hepatitis virus genotype structure in patients with chronic hepatitis C," Zhurnal Mikrobiologii, Epidemiologii, i Immunobiologii, no. 3, pp. 33-38, 2011.

[42] V. Kartashev, M. Döring, L. Nieto et al., "New findings in HCV genotype distribution in selected West European, Russian and Israeli regions," Journal of Clinical Virology, vol. 81, pp. 82-89, 2016.

[43] A. J. Drummond and A. Rambaut, "BEAST: Bayesian evolutionary analysis by sampling trees," BMC Evolutionary Biology, vol. 7, no. 1, p. 214, 2007.

[44] R. Vita, J. A. Overton, J. A. Greenbaum et al., "The immune epitope database (IEDB) 3.0," Nucleic Acids Research, vol. 43, no. D1, pp. D405-D412, 2014.

[45] M. Molero-Abraham, E. M. Lafuente, D. R. Flower, and P. A. Reche, "Selection of conserved epitopes from hepatitis $C$ virus for pan-populational stimulation of T-cell responses," Clinical and Developmental Immunology, vol. 2013, Article ID 601943, 10 pages, 2013.

[46] L. Lebedeva, A. Chumak, T. Pukhlikova, S. Pavlenko, V. Zinkin, and O. Mayorova, "The features of histocompatibility antigens polymorphism of cord blood samples in Moscow Blood Bank," Bulletin of Hematology, vol. 11, no. 2, pp. 2021, 2015.

[47] F. F. González-Galarza, L. Y. C. Takeshita, E. J. M. Santos et al., "Allele frequency net 2015 update: new features for HLA epitopes, KIR and disease and HLA adverse drug reaction associations," Nucleic Acid Research, vol. 43, no. D1, pp. D784-D788, 2015.

[48] M. Andreatta, E. Karosiene, M. Rasmussen, A. Stryhn, S. Buus, and M. Nielsen, "Accurate pan-specific prediction of peptideMHC class II binding affinity with improved binding core identification," Immunogenetics, vol. 67, no. 11-12, pp. 641650, 2015.

[49] I. Hoof, B. Peters, J. Sidney et al., "NetMHCpan, a method for MHC class I binding prediction beyond humans," Immunogenetics, vol. 61, no. 1, pp. 1-13, 2009.

[50] M. Nielsen and M. Andreatta, "NetMHCpan-3.0; improved prediction of binding to MHC class I molecules integrating information from multiple receptor and peptide length datasets," Genome Medicine, vol. 8, p. 33, 2016.

[51] A. K. Akhmineeva, HLA Phenotype and Clinical Course of Chronic Viral Hepatitis, [Ph.D. thesis], Astrakhan State Medical Academy, Astrakhan, 2008.

[52] A. Utama, N. P. Tania, R. Dhenni et al., "Genotype diversity of hepatitis $\mathrm{C}$ virus (HCV) in HCV-associated liver disease patients in Indonesia," Liver International, vol. 30, no. 8, pp. 1152-1160, 2010.
[53] I. Brahim, S. Ezzikouri, E. M. Mtairag et al., "Amino acid substitutions in the hepatitis $C$ virus core region of genotype $1 b$ in Moroccan patients," Infection, Genetics and Evolution, vol. 14, pp. 102-104, 2013.

[54] S. C. Ray, L. Fanning, X. H. Wang, D. M. Netski, E. KennyWalsh, and D. L. Thomas, "Divergent and convergent evolution after a common-source outbreak of hepatitis C virus," Journal of Experimental Medicine, vol. 201, no. 11, pp. 17531759, 2005.

[55] R. Aurora, M. J. Donlin, N. A. Cannon, and J. E. Tavis, "Genome-wide hepatitis $\mathrm{C}$ virus amino acid covariance networks can predict response to antiviral therapy in humans," The Journal of Clinical Investigation, vol. 119, no. 1, pp. 225236, 2008.

[56] Z. Hu, Y. Liu, L. Qiu et al., "Kinetic response of wild and mutant core codon 70 strains of HCV genotype $1 \mathrm{~b}$ to pegylated interferon- $\alpha$ and ribavirin therapy," Virology Journal, vol. 12, no. 1, p. 220, 2015.

[57] K. R. Reddy, J. H. Hoofnagle, M. J. Tong et al., "Racial differences in responses to therapy with interferon in chronic hepatitis C," Hepatology, vol. 30, no. 3, pp. 787-793, 1999.

[58] M. Isaguliants and N. Ozeretskovskaya, "Host background factors contributing to hepatitis C virus clearance," Current Pharmaceutical Biotechnology, vol. 4, no. 3, pp. 185-193, 2003.

[59] Y. Tanaka, N. Nishida, M. Sugiyama et al., "Genome-wide association of $I L 28 B$ with response to pegylated interferon- $\alpha$ and ribavirin therapy for chronic hepatitis C," Nature Genetics, vol. 41, no. 10, pp. 1105-1109, 2009.

[60] C. Fabris, E. Falleti, A. Cussigh et al., "IL-28B rs12979860 C/T allele distribution in patients with liver cirrhosis: role in the course of chronic viral hepatitis and the development of HCC," Journal of Hepatology, vol. 54, no. 4, pp. 716-722, 2011.

[61] Y. Funaoka, N. Sakamoto, G. Suda et al., "Analysis of interferon signaling by infectious hepatitis $\mathrm{C}$ virus clones with substitutions of core amino acids 70 and 91," Journal of Virology, vol. 85, no. 12, pp. 5986-5994, 2011.

[62] N. Akuta, F. Suzuki, M. Hirakawa et al., "Amino acid substitutions in the hepatitis $\mathrm{C}$ virus core region of genotype $1 \mathrm{~b}$ are the important predictor of severe insulin resistance in patients without cirrhosis and diabetes mellitus," Journal of Medical Virology, vol. 81, no. 6, pp. 1032-1039, 2009.

[63] S. Uraki, M. Tameda, K. Sugimoto et al., "Substitution in amino acid 70 of hepatitis $\mathrm{C}$ virus core protein changes the adipokine profile via toll-like receptor $2 / 4$ signaling," PLoS One, vol. 10, no. 6, article e0131346, 2015.

[64] Y. Tachi, Y. Katano, T. Honda et al., "Impact of amino acid substitutions in the hepatitis $\mathrm{C}$ virus genotype $1 \mathrm{~b}$ core region on liver steatosis and hepatic oxidative stress in patients with chronic hepatitis C," Liver International, vol. 30, no. 4, pp. 554-559, 2010.

[65] Y. Sumida, K. Kanemasa, T. Hara et al., "Impact of amino acid substitutions in hepatitis $\mathrm{C}$ virus genotype $1 \mathrm{~b}$ core region on liver steatosis and glucose tolerance in non-cirrhotic patients without overt diabetes," Journal of Gastroenterology and Hepatology, vol. 26, no. 5, pp. 836-842, 2011.

[66] A. V. Ivanov, V. T. Valuev-Elliston, D. A. Tyurina et al., "Oxidative stress, a trigger of hepatitis $C$ and $B$ virus-induced liver carcinogenesis," Oncotarget, vol. 8, no. 3, pp. 3895-3932, 2017.

[67] M. J. Donlin, N. A. Cannon, R. Aurora et al., "Contribution of genome-wide $\mathrm{HCV}$ genetic differences to outcome of interferon-based therapy in Caucasian American and 
African American patients," PLoS One, vol. 5, no. 2, article e9032, 2010.

[68] L. N. Cavalcante, K. Abe-Sandes, A. L. D. Angelo et al., "IL28B polymorphisms are markers of therapy response and are influenced by genetic ancestry in chronic hepatitis $\mathrm{C}$ patients from an admixed population," Liver International, vol. 32, no. 3, pp. 476-486, 2012.

[69] U. Navaneethan, N. Kemmer, and G. W. Neff, "Review: predicting the probable outcome of treatment in HCV patients," Therapeutic Advances in Gastroenterology, vol. 2, no. 5, pp. 287-302, 2009.

[70] J. E. Layden-Almer, R. M. Ribeiro, T. Wiley, A. S. Perelson, and T. J. Layden, "Viral dynamics and response differences in HCV-infected African American and white patients treated with IFN and ribavirin," Hepatology, vol. 37, no. 6, pp. 13431350, 2003.

[71] J. H. Kao, S. H. Ahn, R. N. Chien et al., "Urgency to treat patients with chronic hepatitis C in Asia," Journal of Gastroenterology and Hepatology, vol. 32, no. 5, pp. 966-974, 2017.

[72] N. Enomoto, I. Sakuma, Y. Asahina et al., "Comparison of fulllength sequences of interferon-sensitive and resistant hepatitis $\mathrm{C}$ virus $1 \mathrm{~b}$. Sensitivity to interferon is conferred by amino acid substitutions in the NS5A region," The Journal of Clinical Investigation, vol. 96, no. 1, pp. 224-230, 1995.

[73] M. Ragonnet-Cronin, S. Aris-Brosou, I. Joanisse et al., "Adaptive evolution of HIV at HLA epitopes is associated with ethnicity in Canada," PLoS One, vol. 7, no. 5, article e36933, 2012.

[74] J. Á. Patiño-Galindo and F. González-Candelas, "Comparative analysis of variation and selection in the HCV genome," Infection, Genetics and Evolution, vol. 49, pp. 104-110, 2017.

[75] S. L. Rhodes, H. Erlich, K. A. Im et al., "Associations between the human MHC and sustained virologic response in the treatment of chronic hepatitis C virus infection," Genes \& Immunity, vol. 9, no. 4, pp. 328-333, 2008. 


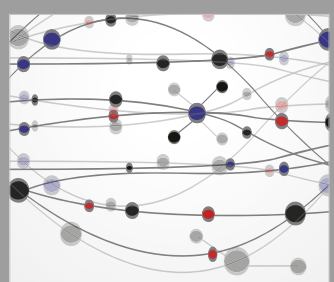

The Scientific World Journal
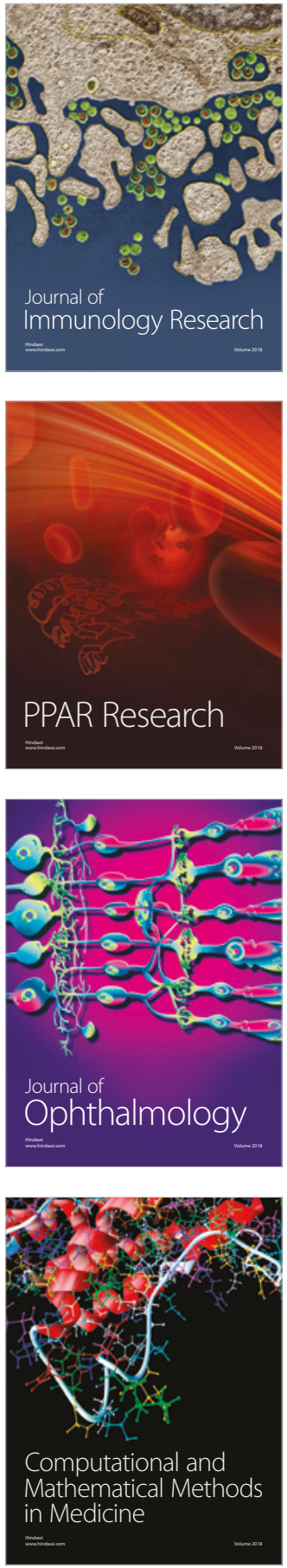

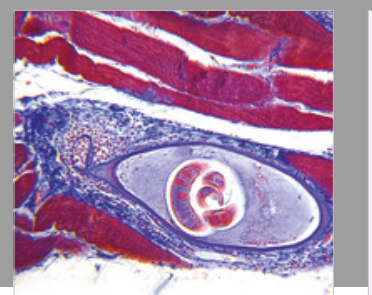

Gastroenterology Research and Practice

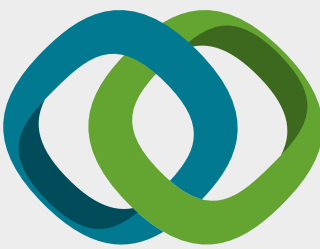

\section{Hindawi}

Submit your manuscripts at

www.hindawi.com
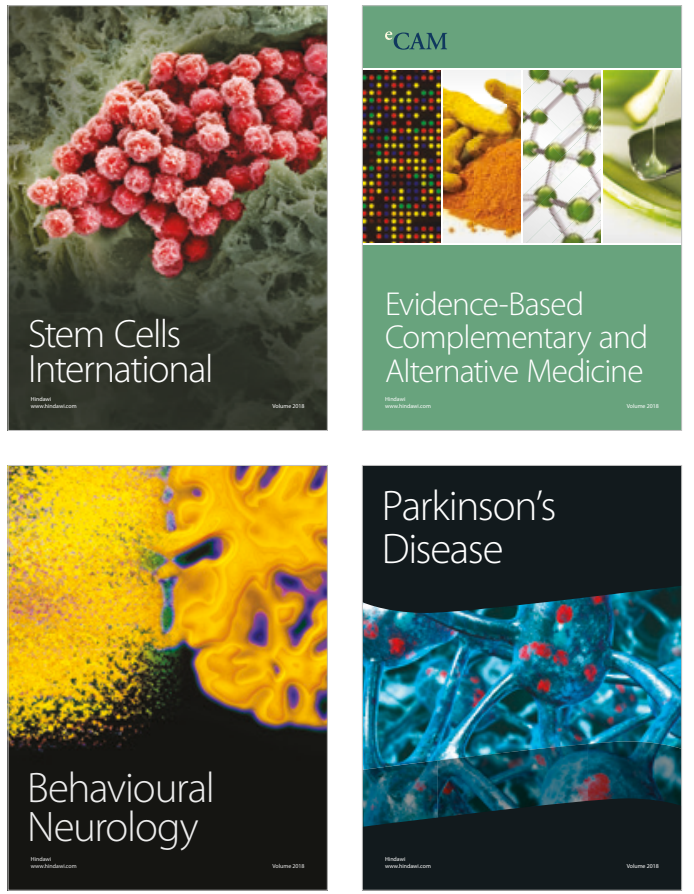

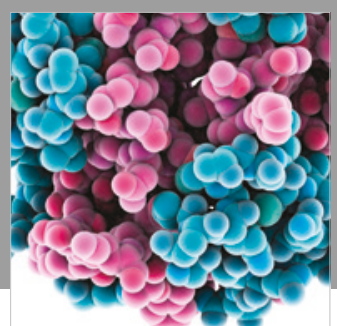

ournal of

Diabetes Research

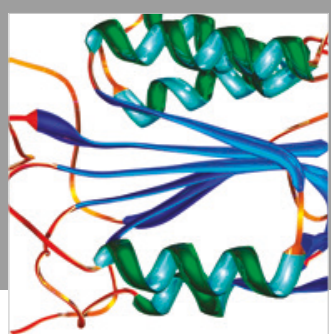

Disease Markers
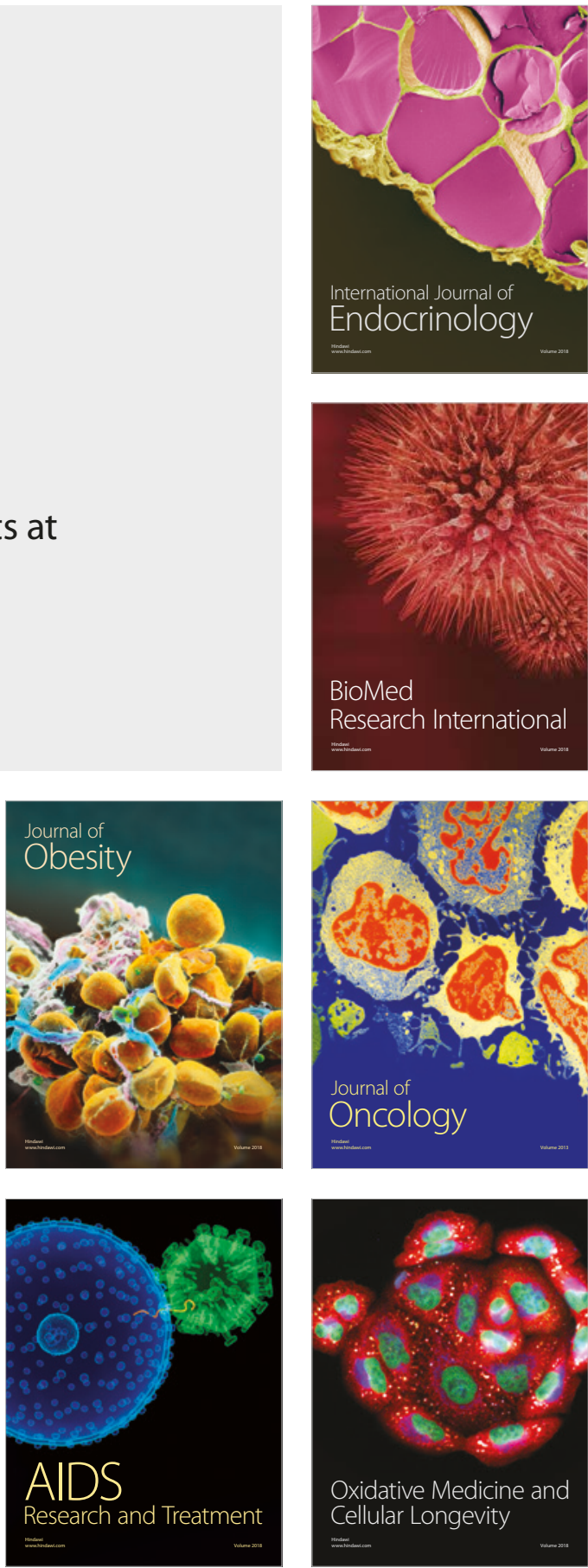